\title{
Novel Composite Electrolyte of Double-Doped Ceria-Sulphate for Medium Temperature Fuel Cells
}

\author{
Wenbao Zhang, Tianhui Hu, Ruijuan Shi**, Hongtao Wang *
}

Anhui Provincial Key Laboratory for Degradation and Monitoring of Pollution of the Environment; School of Chemical and Material Engineering, Fuyang Normal University, Fuyang 236037, China *E-mail: hwang@fynu.edu.cn; rjshi@fynu.edu.cn

doi: $10.20964 / 2020.01 .44$

Received: 9 September 2019 / Accepted: 15 October 2019 / Published: 30 November 2019

In this study, $\mathrm{Gd}^{3+}$ and $\mathrm{Er}^{3+}$ double-doped $\mathrm{CeO}_{2}$ was synthesized by a microemulsion method. $\mathrm{Ce}_{0.8} \mathrm{Er}_{0.1} \mathrm{Gd}_{0.1} \mathrm{O}_{2-\alpha}-\mathrm{K}_{2} \mathrm{SO}_{4}-\mathrm{Li}_{2} \mathrm{SO}_{4}$ composite electrolyte was prepared by mixing $\mathrm{Ce}_{0.8} \mathrm{Er}_{0.1} \mathrm{Gd}_{0.1} \mathrm{O}_{2-\alpha}$ powder with binary sulphates. The structures of $\mathrm{Ce}_{0.8} \mathrm{Er}_{0.1} \mathrm{Gd}_{0.1} \mathrm{O}_{2-\alpha}$ and $\mathrm{Ce} 0.8 \mathrm{Er}_{0.1} \mathrm{Gd}_{0.1} \mathrm{O}_{2-\alpha}-\mathrm{K}_{2} \mathrm{SO}_{4-}$ $\mathrm{Li}_{2} \mathrm{SO}_{4}$ were characterized by X-ray diffraction (XRD) and Raman spectrometer. XRD spectra showed that the $\mathrm{Ce}_{0.8} \mathrm{Er}_{0.1} \mathrm{Gd}_{0.1} \mathrm{O}_{2-\alpha}$ structure was not affected by $\mathrm{K}_{2} \mathrm{SO}_{4}-\mathrm{Li}_{2} \mathrm{SO}_{4}$. Raman spectrometer further indicated that the prepared $\mathrm{Ce}_{0.8} \mathrm{Er}_{0.1} \mathrm{Gd}_{0.1} \mathrm{O}_{2-\alpha}-\mathrm{K}_{2} \mathrm{SO}_{4}-\mathrm{Li}_{2} \mathrm{SO}_{4}$ had a cubic structure of $\mathrm{CeO}_{2}$ and the existence of $\mathrm{SO}_{4}{ }^{2-}$. The maximum conductivity of $\mathrm{Ce}_{0 .} \mathrm{Er}_{0.1} \mathrm{Gd}_{0.1} \mathrm{O}_{2-\alpha}-\mathrm{K}_{2} \mathrm{SO}_{4}-\mathrm{Li}_{2} \mathrm{SO}_{4}$ reached 0.21 $\mathrm{S} \cdot \mathrm{cm}^{-1}$ at $700{ }^{\circ} \mathrm{C}$.

Keywords: Defects; Composite; Electrolytes; Hydrogen; Fuel cell; Conductivity

\section{$\underline{\text { FULL TEXT }}$}

(C) 2020 The Authors. Published by ESG (www.electrochemsci.org). This article is an open access article distributed under the terms and conditions of the Creative Commons Attribution license (http://creativecommons.org/licenses/by/4.0/). 